\title{
O NIVELAMENTO LINGUÍSTICO NO ISF: ENTRE O DESEJO E 0 IMPEDIMENTO
}

\author{
Linguistic placement test in IsF: between the wish and the impediment
}

\author{
Janaína Aguiar Mendes GALVÃO* \\ Alessandra Mara de ASSIS***
}

\begin{abstract}
RESUMO: O objetivo do texto é discutir critérios que justificam o impedimento para o aluno do programa Idiomas sem Fronteiras (IsF) matricular-se em cursos destinados a níveis de proficiência anteriores ao de sua classificação. Tal discussão inscreve-se no grupo de pesquisa GEPADLE/UFTM e também na experiência de coordenação do Nucli/UFTM. Tanto a pesquisa quanto a experiência nos levam à reflexão sobre os conceitos de: 1) nivelamento linguístico, conforme as descrições do Quadro Europeu Comum de Referência para as Línguas (QECR); e 2) pré-requisitos, disciplinas que dispõem a aprendizagem de língua estrangeira (LE) de forma sequencial. Identificamos o primeiro conceito como uma descrição de atividades linguísticas que permitem que o aprendiz de uma LE seja capaz de realizar enunciados concretos na língua aprendida. Por outro lado, o segundo conceito se detém no conhecimento formal de estruturas da LE, calcado em um saber sobre vocabulário e gramática. Identificamos que esta diferença pode aproximá-los dos conceitos bakhtinianos de 'enunciação' e 'sinalidade' (BAKHTIN, 1929), respectivamente. Como conclusão, esperamos ampliar discussões sobre os conceitos tratados e questionar se, de fato, os cursos oferecidos pelo IsF se apresentam como módulos independentes que atendam ao desejo de aprendizagem em LE dos alunos.
\end{abstract}

PALAVRAS-CHAVE:Nivelamento Linguístico; Enunciação;Sinalidade.

\begin{abstract}
The objective of this text is to discuss the criteria that justify the impediment to the student of the Languages Without Borders Program (IdiomassemFronteiras - IsF) from registering in courses that are destined to proficiency levels that are below his/hers. This discussion belongs in the research group GEPADLE/UFTM and it is also an experience in the coordination at Nucli/UFTM. Both the research and the experience have taken us to a reflection on the following concepts: 1) language placement tests, according to the Common European Framework of Reference for Languages (CEFR); 2) requirements, subjects that put foreign language (FL) learning in a sequential way. We have identified the first concept as a description of linguistic activities that make the FL leaner able to state concrete enunciations in the target language. On the other hand, the second concept is reduced to the formal knowledge of the $\mathrm{FL}$ structures, based on what is known about vocabulary and grammar. We have identified that this difference may approximate them to the Bakhtin's concepts of 'utterance' and 'signality' (BAKHTIN, 2006), respectively. As a conclusion, we aim to expand the discussions about the concepts and question if the courses offered by the program are indeed presented as independent modules that cater to the students' wish of learning a FL.
\end{abstract}

KEYWORDS:Linguistic Placement Test; Utterance; Signality.

\section{Introdução}

\footnotetext{
*Mestre em Letras pela Universidade Federal de Minas Gerais, professora adjunta do curso de Letras Português/Espanhol da Universidade Federal do Triângulo Mineiro, pesquisadora do grupo GEPADLE da UFTM e coordenadora geral do Programa Idiomas Sem Fronteiras - Nucli/UFTM.

**Doutora em linguística pela Universidade Federal de Minas Gerais, professora adjunta do curso de Letras Português/Inglês da Universidade Federal do Triângulo Mineiro. Pesquisadora do grupo GEVAR da UFTM, GEFONO da UFU e coordenadora pedagógica de língua inglesa do IsF na UFTM.
} 
O Programa Idiomas sem Fronteiras (IsF) foi iniciado no ano de 2012. Foi criado, de acordo com o site oficial do programa por um "grupo de especialistas em línguas estrangeiras a pedido da Secretaria de Educação Superior do Ministério da Educação (MEC)” (ISF, 2018) para ajudar estudantes de nível superior que fossem participar de programas de mobilidade ofertados pelo Governo Federal a aprender a língua estrangeira (LE) que iriam fazer uso em seu intercâmbio. O programa também ajuda no acolhimento de estrangeiros que passam a morar no Brasil e querem aprender português como LE. É essencial para o processo de internacionalização das universidades, além de dar a oportunidade aos discentes, futuros professores de línguas estrangeiras (LEs), de iniciarem sua experiência como professores, recebendo para tanto orientação de um docente do curso de Letras.

O programa foi instituído dia 16 de agosto de 2012, pela Portaria Normativa $\mathrm{n}^{\mathrm{o}}$ 1.466/2012; na ocasião ele se intitulava 'Inglês sem Fronteiras' e este foi o único idioma oferecido. Ao longo dos anos, várias ações foram promovidas pelo programa, como a aplicação do TOEFL ITP, reuniões de coordenadores, criação do núcleo gestor e dos Nucli, reunião dos representantes das universidades federais, credenciamento dos institutos federais e implantação de outros idiomas, acarretando a mudança do nome do programa para 'Idiomas sem Fronteiras'.

De acordo com o site oficial, o "principal objetivo do Programa é promover ações em prol de uma política linguística para a internacionalização do Ensino Superior Brasileiro, valorizando a formação especializada de professores de línguas estrangeiras” (IsF, 2018).

Nas ofertas de turmas pelo IsF, discentes, docentes e técnicos das instituições de ensino superior podem se inscrever no curso que escolherem, desde que seu nível de proficiência esteja de acordo com o nível exigido nos cursos. Aquelesque estão fora de seu nível de proficiência não aparecem em sua lista de possibilidades. Porém, na UFTM, os cursos que estão sendo oferecidos pelo IsFsão divulgados em nossa página no Facebook, por meio de um mural do Nucli e também através dos plantões de inscrições.Nestes, os bolsistas do programa fornecem informações sobre o IsF e procuram conseguir maior número de alunos nos cursos oferecidos. Com essas iniciativas adotadas, a comunidade passa a ter acesso à informação sobre todos os cursos oferecidos em nosso Nucli. Em casos recorrentes, quando os alunos se deparam com a negativa de efetivarem a matrícula em cursos de seu interesse (destinados a níveis de proficiência anteriores ao seu) manifestam seus questionamentos e sua insatisfação. Vários desses possíveis alunos deixam de se matricular por terem suas expectativas 
frustradas. Esta situação acarreta uma diminuição no número de alunos e, consequentemente, no número de turmas oferecidas pelo Nucli da UFTM.

Assim, o objetivo principal deste texto é questionar e discutir os critérios que respaldam o impedimento para o aluno do programa IsF matricular-se em cursos destinados a níveis de proficiência anteriores ao de sua classificação.

\section{2) Metodologia}

Este trabalho configura-se como uma pesquisa exploratória, valendo-se da pesquisa bibliográfica sobre os conceitos bakhtinianosde enunciação e sinalidade (BAKHTIN, 1929; FARACO, 2003, 2017) e da pesquisa documental ao analisar os critérios de matrícula do IsF e os níveis de proficiência descritos pelo Quadro Europeu Comum de Referência (QECR).

$\mathrm{O}$ interesse por este tema surgiu no âmbito do GEPADLE (Grupo de Estudos e Pesquisas em Análise do Discurso, Leitura e Escrita - UFTM/Fapemig), ao realizar as leituras obrigatórias do grupo para o primeiro semestre de 2018 e, paralelamente, ao buscar a articulação dessas leituras com questões práticas que a experiência de coordenação geral e pedagógica do Nucli/UFTM nos possibilitou, na qual recebemos questionamentos de alunos que requerem participação como ouvintes em cursos nos quais são impedidos de se inscrever.

Este texto desenvolveu-se duranteo segundo semestre de 2018 para apresentação como comunicação oral no I Encontro Nacional do Programa Idiomas sem Fronteiras (I ENPISF), realizado nos dias 18 e 19 de outubro, na Universidade Federal de Uberlândia. Posteriormente, as discussões advindas desta apresentação foram incorporadas ao texto para submissão à revista. Nossa expectativa é continuar esta pesquisa e contribuir para o programa IsF, que é um importante marco nacional para o ensino e a aprendizagem de LEs.

\section{3) Discussão}

O objetivo deste trabalho é discutir critérios que justifiquemesse impedimento de que o aluno do programa IsF possa se matricular em cursos destinados a níveis de proficiência anteriores ao de sua classificação.

Faz-se necessário, portanto, explorar o conceito de nivelamento linguístico, uma vez que ele é parte essencial do programa IsF e imprescindível para quem deseja se matricular nos cursos oferecidos. Este nivelamento é feito conforme as descrições do Quadro Europeu 
Comum de Referência (QECR) e o aluno não consegue efetuar sua matrícula sem antes determinar o nível em que está inserido.

O QECR é o conjunto de parâmetros internacionais que descreve as habilidades linguísticas de um falante de LE. As habilidades são as mesmas trabalhadas regularmente em cursos de LEs: compreensão escrita, produção escrita, compreensão oral e produção oral.

O QECR fornece uma base comum para a elaboração de programas de línguas, linhas de orientação curriculares, exames, manuais, etc., na Europa. Descreve exaustivamente aquilo que os aprendentes de uma língua têm de aprender para serem capazes de comunicar nessa língua e quais os conhecimentos e capacidades que têm de desenvolver para serem eficazes na sua actuação.(CONSELHO DA EUROPA, 2001, p. 19)

É com base nesse quadro que o nível de proficiência do aprendiz que se inscreve no programa é definido, e ele poderá participar de diferentes cursos de acordo com sua classificação que poderá ser: A1, A2, B1, B2, C1 ou C2. CANI e SANTIAGO (2018) destacam o fato de o QECR ter sido discutido e executado antes das tecnologias da comunicação sofrerem um grande avanço, portanto, para as autoras, há lacunas no documento e seria necessário adequar suas práticas contemporâneas às tecnologias digitais. As críticas feitas ao documento fogem do escopo do estudo aqui proposto. Ademais, é forçoso reconhecer a importância que o QECR possui hoje, mundialmente, para o ensino de LEs.

O QECR adota a abordagem plurilinguística ${ }^{1}$, a qual está presente nos três princípios fundamentais apresentados: o currículo, a qualidade do ensino de LE e sua transversalidade. Para o QECR, o plurilinguismo é fundamental para a educação geral em línguas, ainda que suas consequências não tenham sido completamente regulamentadas e postas em prática. Segundo o documento, há várias tentativas para produção de instrumentos que sejam úteis a todos os profissionais de ensino de LE e à promoção do plurilinguismo, pelo fato de colocarem em foco a aprendizagem de línguas a partir de experiências interculturais diversas.

Sendo assim, não basta diversificar o número de LEs oferecidas na escola. Apregoa-se que o indivíduo expandirá sua experiência pessoal com a língua materna (LM), cuja

\footnotetext{
${ }^{1}$ No primeiro deles, afirma-se que o plurilinguismo deve ser o objetivo geral do currículo de línguas, por meio da diversidade linguística e do direito de escolha dos aprendentes dentro do sistema educativo. O segundo princípio defende que é preciso avaliar a eficácia do sistema nas escolas para assegurar a diversificação da oferta de LEs, para abolir repetições desnecessárias quanto ao conteúdo de LEs e para articular o conhecimento de diferentes LEs ao longo da vida escolar. Por fim, o terceiro princípio defende que os currículos devem pautar-se no papel transversal e transferível entre diferentes línguas, no que diz respeito ao conhecimento declarativo e às competências de realização e aprendizagem.
} 
competência comunicativa abrangerá todo o conhecimento e toda a experiência que o indivíduo acumulou enquanto sujeito na sociedade. Assim, ele será capaz de estabelecer uma comunicação eficaz com diferentes interlocutores pertencentes a culturas diversas.

Deste ponto de vista, a finalidade do estudo das línguas modificou-se profundamente. Não se trata já de alcançar 'mestria' em uma, duas ou mesmo em três línguas (cada uma colocada no seu lugar), tendo como modelo final o 'falante nativo ideal'. Em vez disso, a finalidade passa a ser o desenvolvimento de um repertório linguístico no qual têm lugar todas as capacidades linguísticas. Isto implica, evidentemente, que a oferta das línguas em instituições de ensino deva ser diversificada e que os estudantes possam ter oportunidade de desenvolver uma competência plurilíngue. (CONSELHO DA EUROPA, 2001, p. 24)

Consideramos que é necessário apresentar nossas razões para destacar o QECR dentro do contexto do IsF. Nesse sentido, apontamos que o programa estrutura-se a partir de três fundamentos. São eles: o nivelamento linguístico, conforme estabelece o QECR; o curso online, disponibilizado aos alunos que se inscrevem nos cursos do programa; e o curso presencial, ministrado por alunos/professores bolsistas dos cursos de Letras, orientados por um docente do curso, o qual desempenha a função de coordenador pedagógico.

Ressalte-se que a classificação obtida pelo aluno, ao realizar o nivelamento linguístico, é o fator que determinaa quais cursos ele terá acesso e poderá se inscrever. Pode-se observar, no site oficial do IsF, que o nivelamento linguístico é a primeira informação que o aluno interessado no programa recebe a respeito das condições de sua participação. Há também informações sobre outros critérios estabelecidos pelo programa, cujo objetivo principal é viabilizar a internacionalização nas universidades brasileiras, mas que não configuram o objetivo central deste texto. Fato é que, ao buscar a resposta à pergunta: "Posso participar?", os três fundamentos apresentados apontam, em primeiro lugar, aquele que regulará as demais interações do aluno interessado com a lista de cursos elegíveis, no intuito de concretizar sua aprendizagem em LE.

Sendo assim, o nivelamento linguísticoé um conceito afirmado e apreciado pelo programa. Sua descrição, tarefa primordial do QECR, aponta que a LE, enquanto objeto de aprendizagem, afasta-se de um saber unívoco, restrito ao conhecimento especificamente linguístico, no que se refere ao conhecimento formal de estruturas da LE, calcado em um saber sobre vocabulário e regras gramaticais.

O QECR deverá diferenciar as várias dimensões consideradas na descrição da proficiência em língua e fornecer uma série de pontos de referência (níveis ou patamares) que permitam calibrar o progresso na aprendizagem. 
Deve ter-se presente que o desenvolvimento de uma proficiência comunicativa envolve outras dimensões para além da dimensão estritamente linguística (p. ex.: a consciência sociocultural, a experiência imaginativa, as relações afectivas, o aprender a aprender, etc.) (CONSELHO DA EUROPA, 2001, p. 27, grifo nosso.)

Ao descrever a proficiência linguística em LE, o documento afirma uma abordagem orientada para ação, a fim de assegurar que o aprendiz de LE seja capaz de realizar enunciados concretos na língua aprendida. Defende-se que a aprendizagem de LE deve dar-se entre atores sociais que estão inseridos em práticas historicamente situadas, em contextos e domínios de atividades diversas, inseparáveis de sua atividade linguística. Ao retratar a competência comunicativa em LE, o QECR procura abranger diferentes dimensões envolvidas, como se pode verificar abaixo:

A competência comunicativa em língua compreende diferentes componentes: linguística, sociolinguística e pragmática. Cada uma destas componentes é postulada de forma a compreender o conhecimento declarativo, as capacidades e a competência de realização. (CONSELHO DA EUROPA, 2001, p. 34)

A competência linguística abrange as normas do sistema linguístico, osconhecimentos e as capacidades lexicais, fonológicas e sintáticas. A competência sociolinguística diz respeito às normas sociais e culturais de uso da língua, às quais envolvem convenções sociais que se vinculam a diferentes rituais de comunicação de uma comunidade, como por exemplo, às diferentes gerações, à identidade de gênero, à classe social, à atividade profissional etc. A competência pragmática compreende o uso de conhecimentos linguísticos e sócio-linguísticos em situações específicas de interação nas quais os ambientes culturais têm contundente impacto. O QECR, ao propor as especificações para cada nível de classificação, observaaspectos suscitados nesses componentes propostos. Tomemos, como amostra, a descrição da escala global apresentada para o B1 - Nível Limiar:

É capaz de compreender as questões principais, quando é usada uma linguagem clara e estandardizada e os assuntos lhe são familiares (temas abordados no trabalho, na escola e nos momentos de lazer, etc.). É capaz de lidar com a maioria das situações encontradas na região onde se fala a língua-alvo. É capaz de produzir um discurso simples e coerente sobre assuntos que lhe são familiares ou de interesse pessoal. Pode descrever experiências e eventos, sonhos, esperanças e ambições, bem como expor brevemente razões e justificações para uma opinião ou um projecto.(CONSELHO DA EUROPA, 2001, p. 49.)

O trecho acima pertence ao primeiro quadro de descrição dos níveis, no qual se apresentam de forma simples as características globais das diferentes classificações, julgando- 
se que dessa maneira será mais fácil explicitar para um público amplo as orientações compatíveis com atividades de ensino e também com a elaboração curricular. Esta descrição global nos permite afirmar que as especificações se aplicam às situações comunicativas nas quais os estudantes de LE podem interagir. Tais descrições não se pautam em especificar conhecimentos linguísticos de vocabulário, gramática, sintaxe ou morfologia da língua aprendida.

Paralelamente à postulação do nivelamento linguístico conforme o QECR, é preciso caracterizar como o IsF procura descrever o desenvolvimento da proficiência em LE, para além do reconhecimento da importância do nivelamento linguístico para o programa. Constata-se que, ao explicar como se dá a oferta de cursos, sua caracterização é estabelecida por meio de módulos independentes que se vinculam à escolha do candidato. Observemos as informações difundidas no site do IsF:

- Os cursos não são sequenciais, ou seja, não há curso requisito de outro, mas há nível de proficiência ou certificação que permite que o candidato acesse os cursos disponíveis para seu nível.

- Os cursos são modulares e cada candidato escolhe o curso que deseja disponível na oferta.

- O Sistema reconhece o nível de proficiência do candidato e permite somente a visualização da oferta que a universidade fez para o seu nível [...]. (ISF, 2018)

Sendo assim, para o programa, o nivelamento linguístico é o eixo que garante certa autonomia ao estudante de LE, uma vez que lhe permite escolher os cursos de acordo com seus interesses. Por outro lado, os pré-requisitos são preteridos, na medida em que "não há curso requisito de outro". Consideramos que o IsF rompe com a ideia de que o conhecimento em LE seja uma progressão cumulativa e contínua, pautado na sequencialidade, para assumir um arranjo diferente da configuração habitualmente adotada. Tal configuração é organizada pela oferta de disciplinas sequenciais em períodos consecutivos dos currículos de cursos de LE, em todos os segmentos educacionais, seja na escola básica, na universidade ou em cursos de LEs (GALVÃO, 2017).

A inspiração para este novo arranjo vem do próprio QECR e de sua forma de descrever a proficiência linguística. Nesse sentido, o programa afirma o nivelamento linguístico e relega a noção de pré-requisito linguístico para o avanço da aprendizagem, ao defender que o conhecimento em LE se desenvolve em função da exposiçãoadiferentes situações comunicativas nas quais os estudantes são capazes de interagir, bem comoda descrição de suas competências para expressar em LE seus objetivos comunicacionais. Por isso, nossa análise considera que os conceitos de 'nivelamento linguístico' e de 'pré- 
requisito'podem ser colocados em confronto pelo programa. Note-se que no QECR, a descrição da aprendizagem em LE tampouco se configura como um conhecimento acumulativo sobre estruturas ou normas linguísticas:

É necessário relembrar que os níveisreflectem apenas uma dimensão vertical. Têm pouco em conta o facto de a aprendizagem de uma língua constituir tanto uma progressão horizontal como vertical, uma vez que os aprendentes vão adquirindo proficiência para participarem numa gama progressivamente maior de actividades comunicativas. A progressão não consiste meramente numa subida numa escala vertical. Não há nenhuma lógica particular para um aprendente passar por todos os níveis elementares de uma escala. (CONSELHO DA EUROPA, p.40)

A perspectiva de análise que queremos traçar nos oportunizou tomar esses conceitos que identificamos como conflitantes para o IsF- nivelamento linguístico e requisito - em relação a dois conceitos bakhtinianos confrontados. São eles: enunciação e sinalidade. Nossa expectativa, ao cotejar esses pares conceituais, é provocar um questionamentosobre o impedimento de que os alunos do IsF possam se matricular em cursos destinados a níveis de proficiência anteriores ao obtido no teste de nivelamento. Por um lado, acreditamos que nossa crítica encontrará respaldo tanto na proposta do QECR quanto nos pressupostos doIsF. Por outro lado, consideramos que poderemos provocar um deslocamento, no sentido de repensar este impedimentoe propor um novo ângulo enquanto critério para a progressão da aprendizagem em LE.

Para tanto, recorreremos especificamente ao livro "Marxismo e Filosofia da Linguagem" (MFL), publicado em 1929. Abstemo-nos de comentários sobre a autoriado livro e outras curiosidades que cercam o tão conhecido Círculo de Bakhtin, assim como sobre as traduções e a recepção tardia de suas obras no Brasil. Não podemos nos furtar, no entanto, de engrandecer o pensamento dos estudiosos que compuseram este grupo multidisciplinar, porque reconhecemos neleum aporte fértil e inspirador para as ciências humanas e sociais e, em especial, para os estudos sobre a língua e a linguagem. O elogio tecido por Faraco nos dá a dimensão desta contribuição:

Bakhtin pode ser lido como um pensador que dialogou com os problemas filosóficos de seu tempo e, conjugando uma filosofia de valores, uma filosofia da vida e uma filosofia da interação, deu forma concreta e heuristicamente poderosa a projetos apenas visualizados em termos gerais pelos filósofos com quem dialogou, em especial na estética geral e literária e na filosofia da linguagem. (FARACO, 2017. p.55)

Dessa vasta obra, nosso recorte é modesto, ainda que significativo. Em MFL, Bakhtin e Volochinov apresentam uma crítica às duas principais concepções que orientavam os Olhares \& Trilhas | Uberlândia | vol.20, n. 3 | set/dez. 2018 - ISSN 1983-3857 
estudos sobre a língua. Rejeitam tanto o subjetivismo individualista quanto o objetivismo abstrato. O primeiro é rechaçado por restringir a língua a um meio de transmissão do psiquismo individual: "[...] em todo ato de fala, o importante, do ponto de vista da evolução da língua, não são as formas gramaticais estáveis, efetivas e comuns a todas as demais enunciações da língua em questão, mas sim a realização estilística e a modificação das formas abstratas da língua, de caráter individual e que dizem respeito apenas a esta enunciação"(BAKHTIN/VOLOCHINOV, 1999. p.76). O segundo é repelido pelo fato de asseverar que a língua é um sistema abstrato de normas imutáveis que se impõe ao sujeito, excluído de seu contexto, íntimo ou social: "Se, à maneira de alguns representantes da segunda orientação, fizermos dessa separação abstrata um princípio, se concedermos um estatuto separado à forma linguística vazia de ideologia, só encontraremos sinais e não mais signos da linguagem. A separação da língua de seu conteúdo ideológico constitui um dos erros mais grosseiros do objetivismo abstrato"(BAKHTIN/VOLOCHINOV, 1999. p.96).

Sendo assim, os conceitos de enunciação e sinalidade serão suficientemente úteis para tornar mais complexa nossa compreensão sobre o que significa aprender e ensinar uma LE, principalmente porque,em MFL, o contraste entre língua materna (LM) e LE é um tópico importante para favorecer a apreensão da relação existente entre estes dois conceitos que nos interessam, bem como de outros que a eles se relacionam. Por exemplo:

No processo de assimilação de uma língua estrangeira, sente-se a "sinalidade" e o reconhecimento, que não foram ainda dominados: a língua ainda não se tornou língua. A assimilação ideal de uma língua dá-se quando o sinal é completamente absorvido pelo signo e o reconhecimento pela compreensão. (BAKHTIN/VOLOCHINOV, 1999. pp. 94-95)

Bakhtin e Volochinovrecorrem inúmeras vezes a diferenças identificadas entre LM eLE para revelar o verdadeiro "núcleo da realidade linguística" (p.89), cuja premissa recai sobre a enunciação, que mesmo sendo inseparável da sinalidade, precisa superá-la. Nas palavras dos autores, um fragmento da nota de rodapé que explica o trecho anteriormente citado:

um método eficaz e correto de ensino prático exige que a forma seja assimilada não no sistema abstrato da língua, isto é, como uma forma sempre idêntica a si mesma, mas na estrutura concreta da enunciação, como um signo flexível e variável. (BAKHTIN/VOLOCHINOV, 1999. p. 95)

Em recorrências abundantes que não nos dispusemos a quantificar no corpo do texto,os autores advertem sobre a relevância do sinal, quando é caracterizado como inusual, 
exótico, na própria LM, e também quando a língua ainda é desconhecida. Porém, sua insistência volta-se sempre à enunciação, a qual excede o reconhecimento da sinalidade:

É impossível reduzir-se o ato de descodificação ao reconhecimento de uma forma lingüística utilizada pelo locutor como forma familiar, conhecida modo como reconhecemos, por exemplo, um sinal ao qual não estamos suficientemente habituados ou uma forma de uma língua que conhecemos mal. Não; o essencial na tarefa de descodificação não consiste em reconhecer a forma utilizada, mas compreendê-la num contexto concreto preciso, compreender sua significação numa enunciação particular. Em suma, trata-se de perceber seu caráter de novidade e não somente sua conformidade à norma. Em outros termos, o receptor, pertencente à mesma comunidade lingüística, também considera a forma lingüística utilizada como um signo variável e flexível e não como um sinal imutável e sempre idêntico a si mesmo. (BAKHTIN/VOLOCHINOV, 1999. p. 93)

Seria pertinente considerar o sinal em LE como uma novidade em si? Tendemos a afirmar que sim, ainda que nos pareçam insuficientes para "penetrar na corrente da comunicação"(BAKHTIN/VOLOCHINOV, 1999. p. 108)e da aprendizagem de uma LE.

\section{4) Conclusão}

Acreditamos que propor módulos independentes para o ensino de LE é afirmar que os sinais, reconhecidos ou desconhecidos, não são o núcleo da aprendizagem de LEs. Tanto o QECR quanto o IsF demonstram que o conhecimento em LE pauta-se em contextos de interação possíveis de concretude, projetando nas situações de aprendizagem uma possibilidade de experiência social quepermanentemente se atualizará na exposição à LE. O nivelamento linguístico postula a descrição de diferentes níveis de interação presumíveis, a fim de que o aluno construa enunciados cada vez melhores em LE, até alcançar o ápice da totalidade da língua, como descrito no último estágio do nivelamento, C2 - usuário proficiente:

É capaz de compreender, sem esforço, praticamente tudo o que ouve ou lê. É capaz de resumir as informações recolhidas em diversas fontes orais e escritas, reconstruindo argumentos e factos de um modo coerente. É capaz de se exprimir espontaneamente, de modo fluente e com exactidão, sendo capaz de distinguir finas variações de significado em situações complexas. (CONSELHO DA EUROPA, 2001. p.49)

Conjeturamos que a facilidade somente pode incidir no plano da sinalidade, supondo que o aluno que alcança este último nível já não "sente a sinalidade", pois a "língua já se tornou língua". Dessa forma, as dificuldades que se apresentarem não estarão circunscritas àsinalidade, seus esforços já não precisarão voltar-se aos sinais, na qualidade de“novidade” da LE(BAKHTIN/VOLOCHINOV, 1999. pp. 94-95). Ao conquistar o nível C2, o aluno já terá 
constituído um conhecimento linguístico de LE (fonético, morfológico, sintático, semântico e pragmático - embora ignore teoricamente o que significam) que lhe permitirá compreender "praticamente" tudo, nunca inteiramente, uma vez que, na prática, cada enunciado é sempre inédito e pode continuamente tornar-se outro, ao distinguir "finas variações de significado em situações complexas”(CONSELHO DA EUROPA, 2001. p.49).

Para lograr o último estágio, o aluno depende de uma avaliação objetiva, cumprida no âmbito de um curso ou de um teste de proficiência ${ }^{2}$. Entretanto, conceber que esta avaliação cabe exclusivamente a um professor ou a um exame de proficiência desconsidera o aluno como sujeito de sua enunciaçãoe, conforme entendemos com Bakhtin, é este o objetivo que professores e alunos deveriam buscar ao ensinar e ao aprender uma LE. É preciso receber como compreensão ativa do processo de aprendizagem de LE, por parte do aluno, seus interesses individuais, que se manifestam no decorrer de seu desenvolvimento em LE, reconhecendo a importância de suas impressões subjetivas, como indivíduo que pretende inserir-se em uma comunidade que lhe requer a manifestação de seu conhecimento em LE.

É no respeito ao direito de arbítrio dos alunos que, no Nucli da UFTM,temos permitido que eles frequentem, ainda que como ouvintes, aqueles cursos nos quais desejam se inscrever, mesmo impedidos pelo sistema. Acreditamos que, se o aluno deseja participar de um determinado curso, não devemos privá-lo dessa potencial interação com a LE, porque não podemos defender, ao apoiar-nos nos conceitos bakhtinianos de enunciação e sinalidade, que a aprendizagem de LE esteja condicionada ao conhecimento de formas e normas já reconhecidas da LE, mas sim na possibilidade de torná-las signos de sua enunciação concreta, superando a mera sinalidade. $\mathrm{O}$ desejo do aluno em participar voluntariamente de um curso modular é um incentivo para que realize enunciações concretas em LE, possibilitando sua compreensão de "praticamente tudo" e reconhecendo uma evolução ininterrupta em seu processo de aprendizagem em LE.

O impedimento de sua matrícula reduz suas potenciais enunciações ao plano inferior da sinalidade, o que obstrui tanto seus enunciados (eventos únicos e irrepetíveis) quanto sua interação com a comunidade linguística da qual almeja fazerparte. Em contradição a este impedimento, localizamos premissas afirmadas pelo QECR e pelo IsF.

\footnotetext{
${ }^{2}$ De acordo com Galvão e Tibúrcio, a avaliação realizada pelo professor não deveria estar restrita aos resultados objetivos obtidos pelos alunos em termos de notas ou conceitos atribuídos, mas também por meio da reflexão do professor sobre as enunciações que se concretizam em sala de aula, o que lhe possibilita avaliar sua prática docente e sua apreciação a respeito dela. (GALVÃO e TIBÚRCIO, 2018. No prelo.)
} 
Com efeito, asinalidade em LE poderá não ser reconhecida. Não obstante, sempre se poderá apresentá-la. A ação didática sugerida é selecionar os sinais que precisamos apresentar e reconhecer para que os alunos enunciem, concretamente, em LE.O que jamais se dará sem esforço, devido a inúmeras dificuldades que se impõem: não é possível saber quais são todos os sinais a serem aprendidos (e cada um deles, em seu devir de signo) por meio de generalizações precisas, uma vez que os enunciados são eventos inéditos, únicos e irrepetíveis. Porém,são eles o cerne da enunciação que pertence à sala de aula de LE, que é igualmente única e deriva de seus sujeitos com seus contextos.

Também haverá outros conceitos para rastrear os elementos que se conjugam para constituir uma enunciação: signo, tema, discurso. Há muitos mais, mas nosso recorte modesto não poderia querer abarcá-los. Ainda assim, poderíamos sugeri-los. Por exemplo: como poderíamos caracterizar o interdiscurso em LE? A língua materna? Não pode ser somente ela. É fundamental aclarar que, com o termo 'somente', não nos referimos aos sinais, porque também são infinitos e diversos. Parecem estar ao mesmo tempo na fonética, morfologia, sintaxe, semântica, pragmática, e como suposição, por meio da riqueza dessa diversidade, teríamos livre acesso a todos. Não obstante, o sinal não será nunca o mesmo signo, tal como nos demonstra Faraco.

[...] o plano da sinalidade é parte constitutiva do plano da significação do enunciado. Assim, sua semântica comportaria necessariamente duas dimensões em estreita correlação: a significação dada pela estrutura (reiterável e sempre igual) e a significação dada pela enunciação (o sempre mutável e adaptável) - ou seja, o mesmo (sinal) que é sempre outro (signo). (FARACO, 2003. p.95)

A este todo sempre inacabado, sempre serão acrescidos outros mais que, num recorte modesto, não se poderá abordar. Na verdade, teríamos que criar novos conceitos ou, pelo menos, garantir-lhes alguma "novidade" dentro de todas as atividades linguísticas que se realizam nas aulas de LE, ora como enunciação, ora comosinalidade, ora coincidentes. Sim e não, pois a relação é sempre dialógica, de forma que algumas delas, sim, funcionam, mas outras não. E a depender do grupo, da turma, dos materiais, e de um infinito que é sempre variável, sim e não se invertem. Resta-nos tomar a aula de LEcomo 'tema', já tão constante na vida e no trabalho de todo professor, para apreciá-la, entregá-la à arena, em LE, com a missão de que, em sua totalidade e em seu inacabamento, o objeto de conhecimento torne-se LÍNGUA. E, para este feito, precisaremosvencer a nós mesmos sem derrotá-la, porque nunca se poderá detê-la, tampouco deixar de buscá-la. Do contrário, será ela quem nos abandonará. 
Galvão, Assis | p. 81 - $93 \quad$ O nivelamento linguístico no IsF: entre o desejo e o impedimento ...

Consola-nos a possibilidade de que sempre haverá novos caminhos e formas para aprender, bem como para ensinar, uma LE. A única garantia é que falta alguma coisa que sempre vamos perseguir por meio da(s) língua(s) que nos permitem existir.

\section{Referências}

BAKHTIN, M. (VOLOCHINOV). Marxismo e filosofia da linguagem: Problemas fundamentais do método sociológico na ciência da linguagem. 9 ed. Trad. Michel Lahud e Yara Frateschi Vieira. São Paulo: HUCITEC, 1999.

CONSELHO DA EUROPA. Quadro Europeu Comum De Referência Para As Línguas Aprendizagem, ensino, avaliação. Colecção: Perspectivas Actuais/ Educação Edições Asa. Porto, 2001.

FARACO, C.A. Linguagem e diálogo: as idéias linguísticas do círculo de Bakhtin. Curitiba: Criar Edições, 2003.

Bakhtin e filosofia. Bakhtiniana, São Paulo, 12 (2): 45-56, Maio/Ago. 2017.

GALVÃO, J. A. M. Problematizações a respeito dos pré-requisitos no ensino de língua espanhola. In: BARBOSA, M. V., MORAES, C. F e VIDAL, M.E.B. (org.) Teorias de Linguagem: Pesquisa e Ensino. Campinas: Mercado de Letras, 2017.

. e TIBURZIO, V.L.B. Percepções dos professores sobre as mudanças no desempenho escolar de alunos participantes do Pibid. (No prelo).

IDIOMAS SEM FRONTEIRAS. Disponível em: <http://isf.mec.gov.br> Acesso em 17 out.2018. 